\title{
Printed Modified Bow-Tie Dipole Antenna for DVB/WLAN Applications
}

\author{
Ching-Chih Hung, Chia-Mei Peng, and I-Fong Chen \\ Department of Electronic Engineering, Institute of Computer and Communication Engineering, Jinwen University of \\ Science and Technology, No. 99 An-Chung Road, Hsintien City 23154, Taipei, Taiwan
}

Correspondence should be addressed to I-Fong Chen; ex0206@just.edu.tw

Received 28 April 2013; Revised 24 June 2013; Accepted 27 June 2013

Academic Editor: Bal Singh Virdee

Copyright (C) 2013 Ching-Chih Hung et al. This is an open access article distributed under the Creative Commons Attribution License, which permits unrestricted use, distribution, and reproduction in any medium, provided the original work is properly cited.

\begin{abstract}
A printed modified bow-tie dipole antenna which consists of asymmetric-feed and inserted slots is presented to apply to the DVB and WLAN systems. This antenna combines omnidirectional radiation pattern, broad bandwidth, and band rejection in an easy way to fabricate. Experimental results of the constructed prototype indicate that the VSWR $2.5: 1$ bandwidths achieve $166.7 \%$, 28.57\%, and $23.63 \%$ at $660 \mathrm{MHz}, 2450 \mathrm{MHz}$, and $5500 \mathrm{MHz}$, respectively.
\end{abstract}

\section{Introduction}

An increasingly popular paradigm for wireless communications considers clusters of cooperating networks, which offer the user seamless access through a range of technologies such as digital video broadcasting (DVB, UHF band: 470$862 \mathrm{MHz}$ ) and wireless local area network (WLAN, ISM bands: $2.4-2.4835 \mathrm{GHz}$ and $5.15-5.825 \mathrm{GHz}$ ) [1]. The interworking wireless technologies, such as WLAN with DVB networks, provide the user with a return link for interactive TV and high bandwidth asymmetric downlink for data transfer to terminals operating in the heterogeneous roaming environment. Therefore, the desired antenna design must be able to cover both DVB and WLAN systems at the same time and to include dual-band/broad bandwidth, simple impedance matching to the feed line, and low profile. The bow-tie dipole antenna has become the main candidate for the above application since its bandwidth performances are reasonably better than other alternatives [2]. However, it is difficult for the traditional printed bow-tie dipole antenna to meet multiband operation for respective communication systems. The solution is to design a dual- or multiband integrated antenna for wireless product applications. For this purpose, in this paper, we introduce a printed modified bowtie dipole antenna which combines band-rejection slots and asymmetric-feed structure to yield three operating bands
[3]. The printed modified bow-tie dipole arms adjustable in position will yield an asymmetrical structure. The impedance matching is obtained through tuning the shifted distance of the arms [4]. The band rejection is obtained by inserting some slots in the dipole arms [5-9]. Details of the specification of the proposed designs and the experimental results of constructed prototype are presented and discussed in the following sections.

\section{Antenna Structure and Design}

Figure 1 shows the proposed asymmetric modified bowtie dipole antenna for DVB and WLAN applications. The presented antenna structure is composed of a modified bowtie dipole radiating element section of length $L$, width $W$, flare angle $\theta$, and shifted distance $D$, which is printed on a $1.6 \mathrm{~mm}$ thick FR4 glass epoxy substrate (the relative permittivity is 4.3). The fundamental resonant mode of modified bow-tie dipole is designed to occur at about $660 \mathrm{MHz}$ (the center frequency of the lower operating band: $470-862 \mathrm{MHz}$ ). The dipole length and width can be determined from the halfand quarter-wave lengths of the resonant frequencies. Note that the flare angle of modified bow-tie dipole is a function of operating bandwidth. In general, the bandwidth of the lower operating band increases with an increase in the flare angle. By determining appropriate dimensions $(L, W, D$, and $\theta)$ 


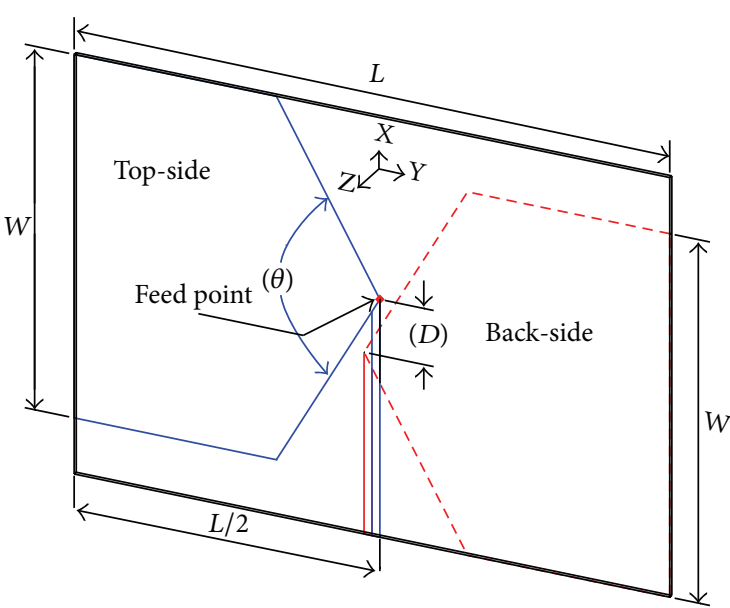

(a)

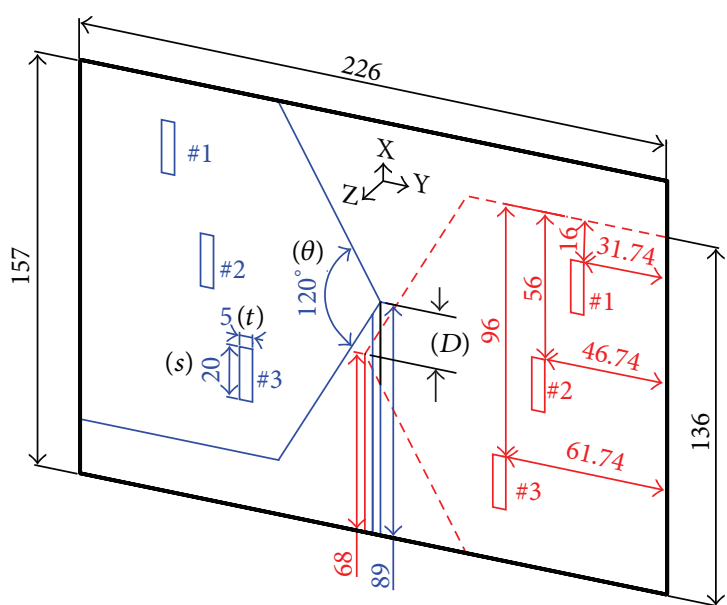

(b)

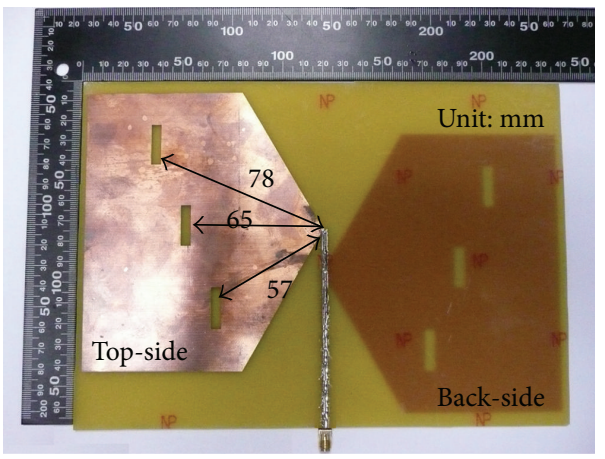

(c)

Figure 1: (a) Geometry of the original antenna. (b) Geometry of the proposed antenna. (c) Implemented prototype of the proposed antenna.

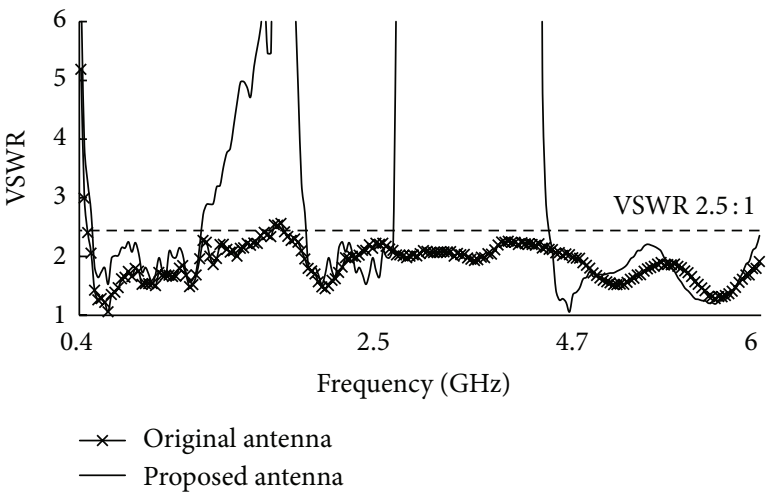

(a)

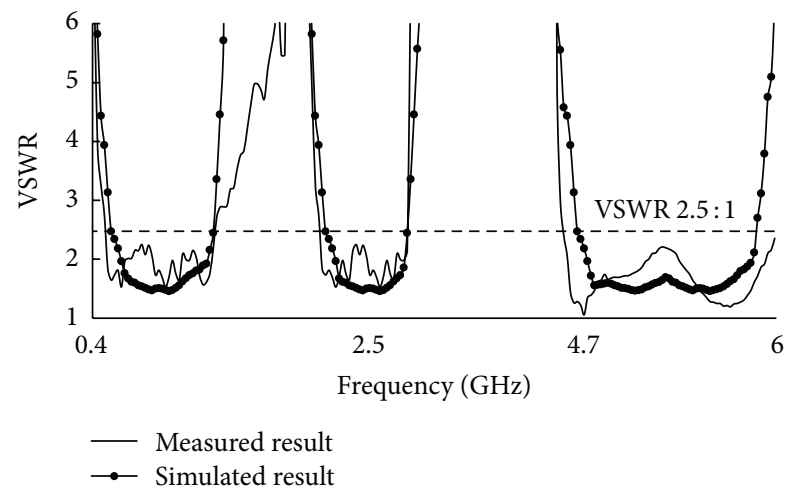

(b)

FIGURE 2: (a) Measured VSWR against frequency of the original and proposed antenna. (b) Measured and simulated VSWR against frequency of the proposed antenna.

of the antenna structure, good impedance matching of the printed modified bow-tie dipole can be obtained across an extended bandwidth. A parallel-strip feed excites the modified bow-tie dipole arms with shifted distance $D$ to be of asymmetric structure as shown in Figure 1(a), denoted as the original antenna. The shape of the original antenna is designed for wideband operation. For fitting in with a $50 \Omega$ feed system and to obtain an extended bandwidth, the shifted distance $D$ should be $\lambda / 20$ [4]. The band rejection of the dipole structure is obtained by inserting some slots in the dipole arms. Note that the size and number of the slots are not identical. The impedance matching at UHF band (470$862 \mathrm{MHz})$ and dual ISM band $(2.4 \mathrm{GHz}$ and $5.8 \mathrm{GHz})$ can be tuned by adjusting the size of the slots on the dipole arms. 


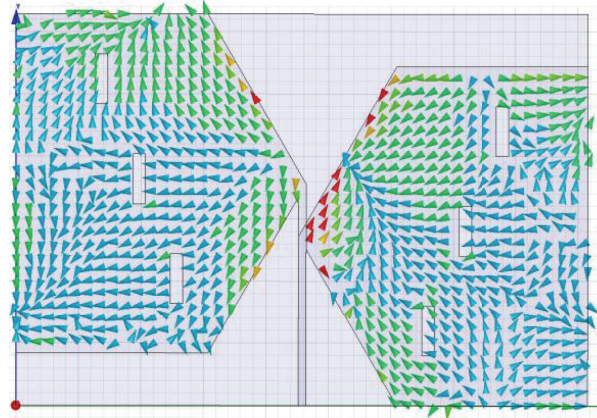

$660 \mathrm{MHz}$ current distribution

(a)

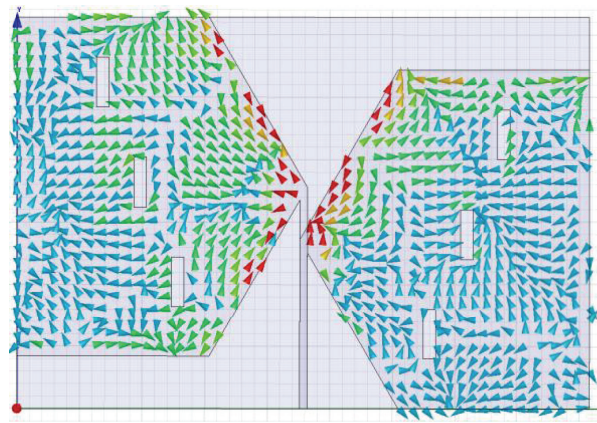

$2450 \mathrm{MHz}$ current distribution

(c)

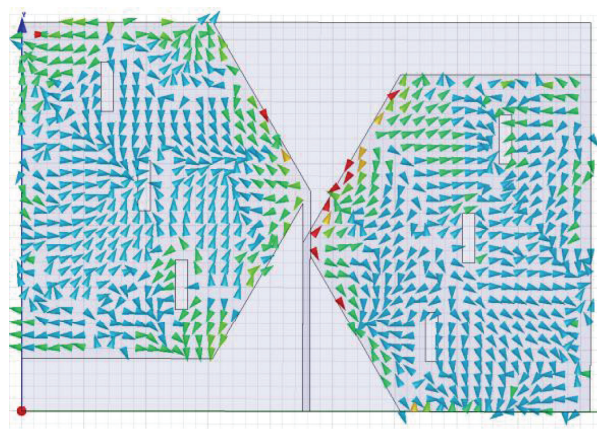

$5500 \mathrm{MHz}$ current distribution

(e)

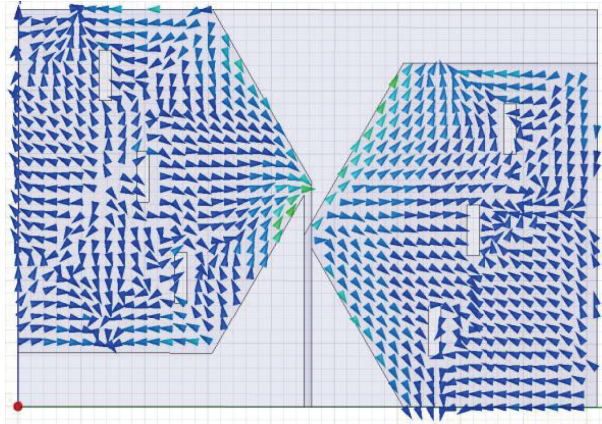

$960 \mathrm{MHz}$ current distribution

(b)
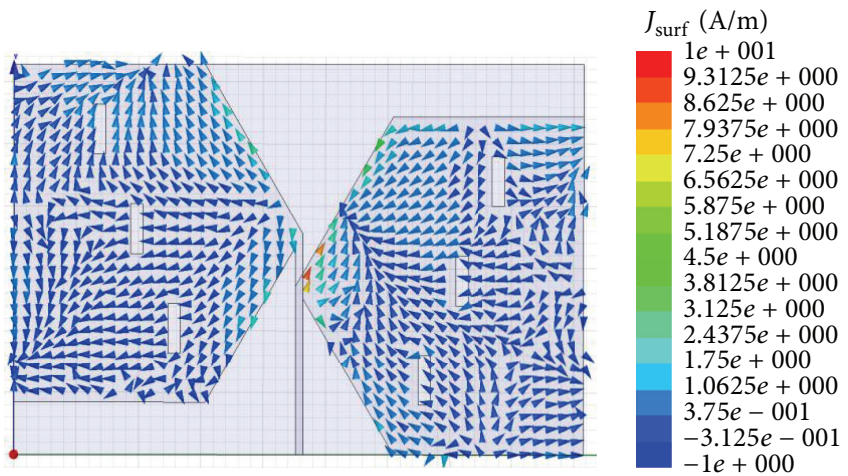

$1300 \mathrm{MHz}$ current distribution

(d)
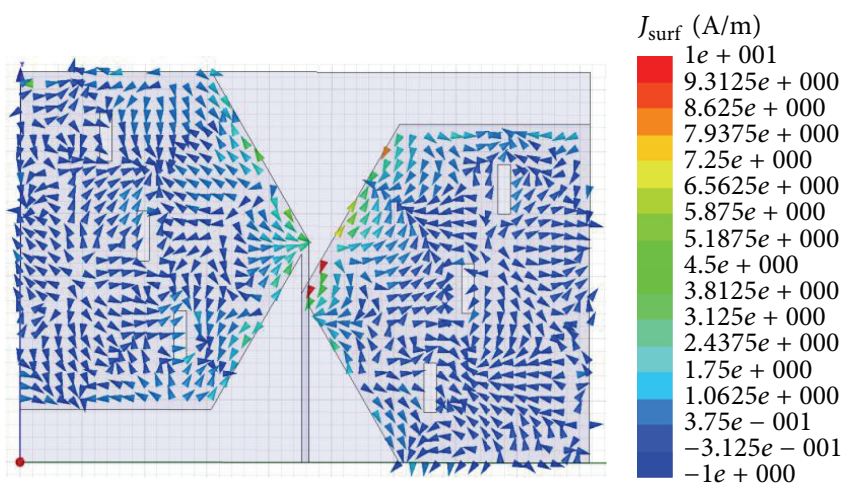

$3900 \mathrm{MHz}$ current distribution

(f)

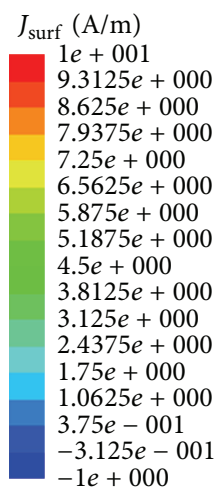

FIGURE 3: Simulated current density versus frequency on the modified bow-tie dipole arms.

\section{Experimental Results and Discussion}

In the experiment, the parallel-strip feed of the proposed antenna is connected to a $50 \Omega$ SMA connector. By using the described design procedure, the original antenna is constructed to operate the VSWR $\leq 2.5$ in the range of $450 \mathrm{MHz}$ to $6 \mathrm{GHz}$, as shown in Figure 2(a), with modified bow-tie dipole-arm's size: length $L=22.6 \mathrm{~cm}$, width $W=$ $13.6 \mathrm{~cm}$, flare angle $\theta=120^{\circ}$, and shifted distance $D=$ $2.1 \mathrm{~cm}$ [4]. Based on the experimental studies, the effects of key parameters (e.g., slots location, slots sizes, and slots

.



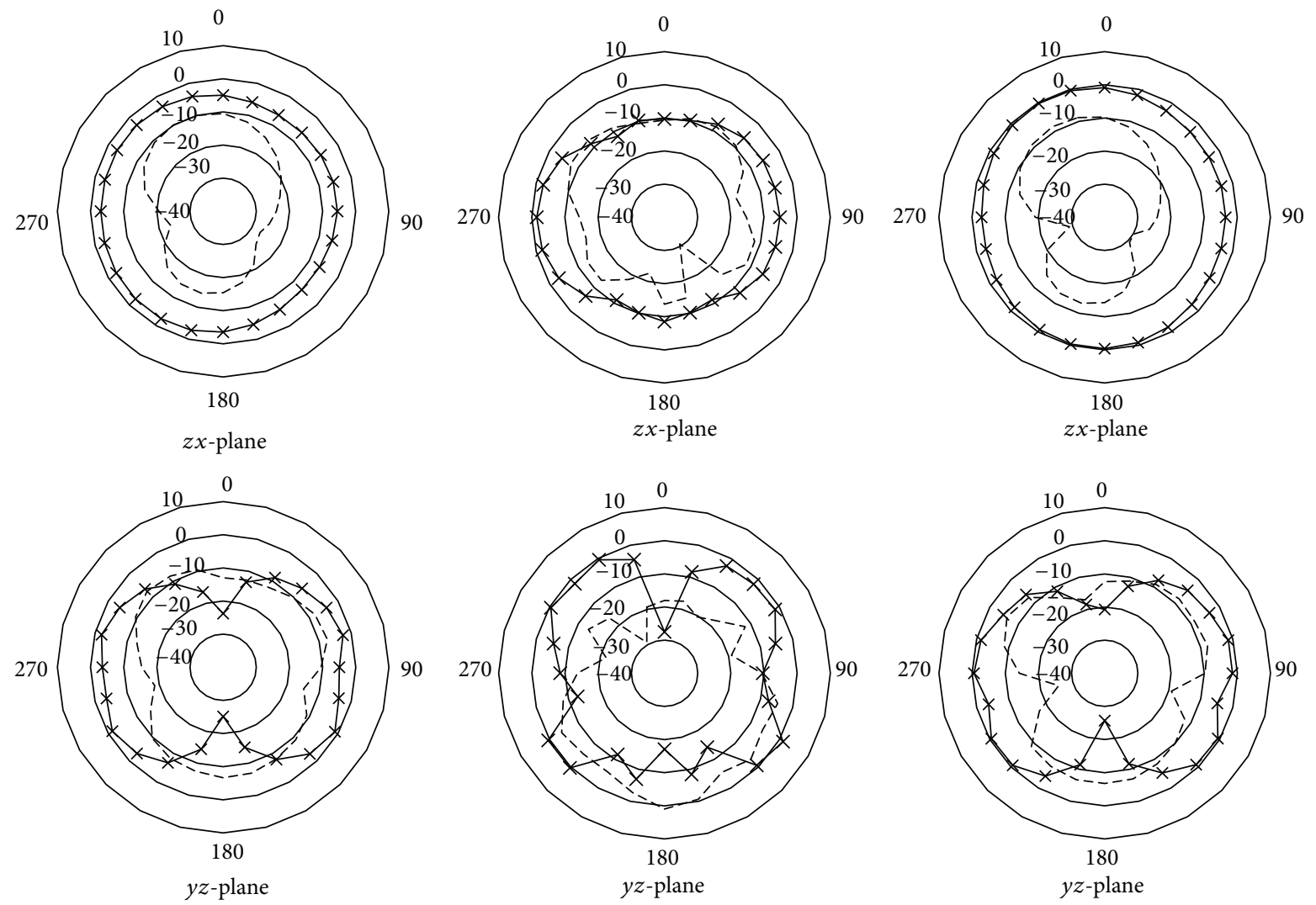

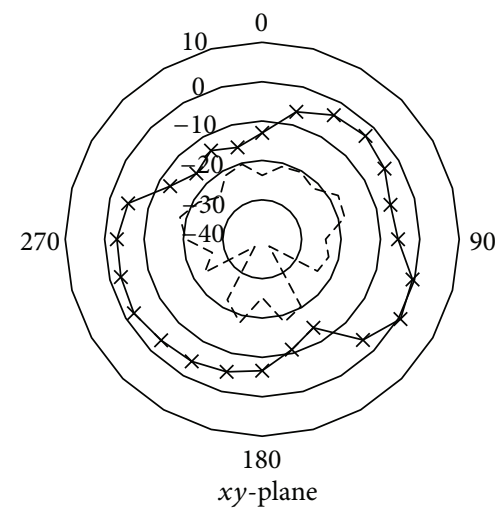

(a)

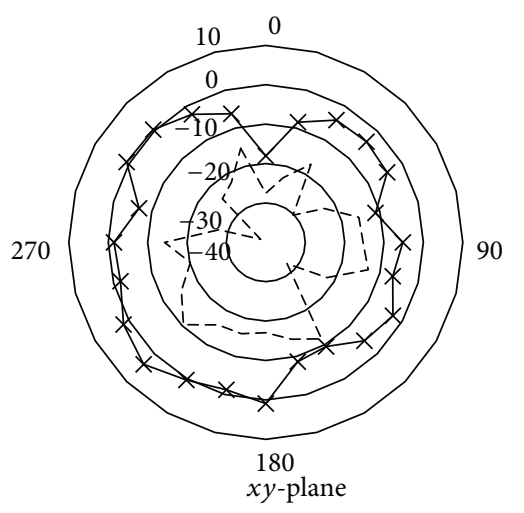

(b)

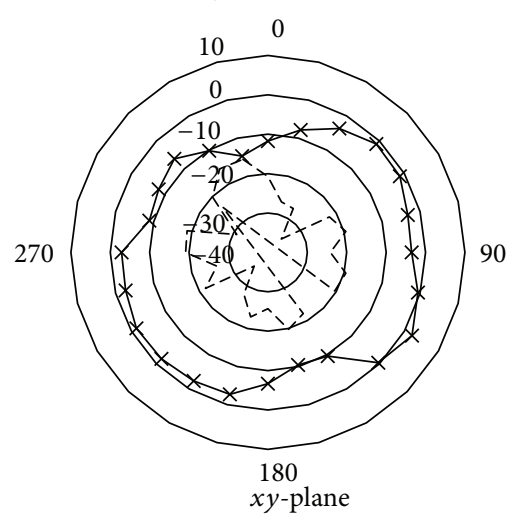

(c)

FIGURE 4: Measured radiation patterns for the proposed antenna (-x-copolar.-cross-polar.). (a) $660 \mathrm{MHz}$, (b) $2450 \mathrm{MHz}$, and (c) $5500 \mathrm{MHz}$.

(23.63\%) at $660 \mathrm{MHz}, 2450 \mathrm{MHz}$, and $5500 \mathrm{MHz}$, which meet the required bandwidths of the DVB and WLAN systems. The simulated results are obtained by using the Ansoft HFSS. We can also find that a good agreement between the simulation and the measurement is obtained. The simulation results of the current density on the proposed antenna are shown in Figure 3. Because the impedance mismatching at $960 \mathrm{MHz}, 1300 \mathrm{MHz}$, and $3900 \mathrm{MHz}$ results in the surface current density being lower than $660 \mathrm{MHz}, 2450 \mathrm{MHz}$, and $5500 \mathrm{MHz}$, the slots are located at quarter-wave length of the undesired frequencies from the feed point that has also been verified.

Figure 4 presents the measured radiation patterns for free space in the $y z$-plane (E-plane) and the $z x$-plane (H-plane).
The maximum gains in the E-plane and $\mathrm{H}$-plane are $0.13 \mathrm{dBi}$, $1.27 \mathrm{dBi}$, and $1.04 \mathrm{dBi}$ and $0.09 \mathrm{dBi}, 0.04 \mathrm{dBi}$, and $0.11 \mathrm{dBi}$, respectively, at $660 \mathrm{MHz}, 2450 \mathrm{MHz}$, and $5500 \mathrm{MHz}$. The gain response with frequency is shown in Figure 5, indicating that the effect of band rejection is remarkable. Table 1 shows the measured antenna gains and 3D pattern efficiency within the operating bands of the proposed antenna. Stable radiation patterns are observed. The total $3 \mathrm{D}$ pattern efficiency is defined as (gain/directivity) $\times 100 \%$, which was done by using pattern integration employing the ETS-Lindgren anechoic chamber. Acceptable radiation characteristic for the practical applications is obtained for the proposed antenna. The omni-directional feature of the proposed antenna can also be observed from the horizontal plane. The operating 
TABLE 1: The measured antenna gains within the operating bandwidth of the proposed antenna.

\begin{tabular}{lcccc}
\hline Frequency (MHz) & \multicolumn{2}{c}{$H$-plane $(z x$-plane) } & $\begin{array}{c}\text { E-plane }(y z \text {-plane }) \\
\text { Max. gain }\end{array}$ & $\begin{array}{c}\text { 3D pattern } \\
\text { Efficiency }(\%)\end{array}$ \\
\hline 470 & Max. gain & Avg. gain & 0.19 & 51.22 \\
660 & -2.37 & -4.43 & 0.13 & 56.56 \\
860 & 0.09 & -3.77 & 0.94 & 58.71 \\
2400 & 0.91 & -3.03 & 0.43 & 66.45 \\
2450 & 0.06 & -3.76 & 1.27 & 65.52 \\
2500 & 0.04 & -3.61 & 1.43 & 68.72 \\
5150 & 0.06 & -3.15 & 0.93 & 69.71 \\
5500 & 1.01 & -2.76 & 1.04 & 71.23 \\
5850 & 0.11 & -3.31 & 1.76 & 70.52 \\
\hline
\end{tabular}

Max.: maximum and Avg: average.

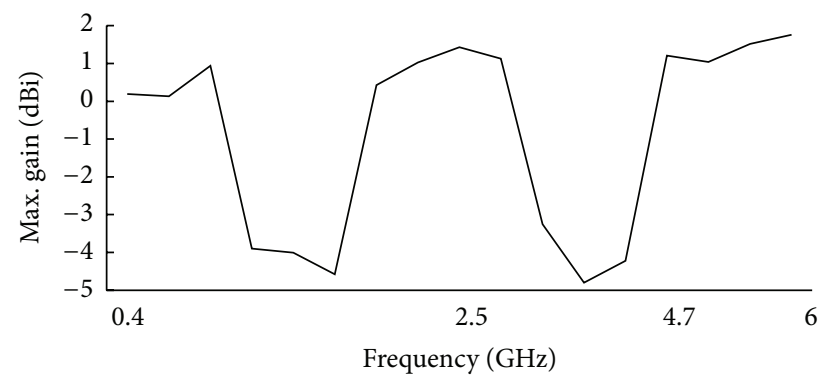

FIGURE 5: Measured antenna gain versus frequency.

bandwidth of the proposed antenna with usable broadside radiation patterns is consistent with the specification of DVB and WLAN systems.

The effect on the antenna performance by varying the insertion-slot numbers and dimensions has been studied, and the results are described below. The structure of insertion slot is a rectangular slot, as shown in Figure 1(b). The corresponding characteristics of resonant frequency, input impedance, and bandwidth are a function of the geometrical parameters of the insertion-slot structure. The experimental results of varying insertion-slot numbers and sizes were obtained by measurement, as shown in Figure 6. According to the above analyses, it is obvious that the inserted slots are used for the band rejection. Figure 6(a) shows impedance characteristics with various numbers of inserted slots, which control the operating bands. Measurement results show that by inserting three slots, the desired operating bands can be obtained. In the UHF band, an increase in the insertionslot length $(s)$ leads to an increase in impedance bandwidth. Contrarily, the insertion-slot length $(s)$ has a negative effect on impedance bandwidth in the dual-ISM band; the measurement results are shown in the Figure 6(b). On the other hand, an increase in the insertion-slot width $(t)$ leads to a decrease in impedance bandwidth in the UHF band, while in the dualISM band, there is a positive relation between insertion-slot width $(t)$ and impedance bandwidth, as shown in Figure 6(c). The optimal slot sizes of length $(s)$ and width $(t)$ are $20 \mathrm{~mm}$ and $5 \mathrm{~mm}$, which will provide the appropriate operating band for DVB and WLAN system applications.

\section{Conclusion}

It has been demonstrated that a printed modified bow-tie dipole provides multiband operation. By correctly choosing the width of the slots, three bandwidths, defined for a VSWR lower than 2.5, achieving $166.71 \%, 28.57 \%$, and $23.63 \%$, respectively, at $660 \mathrm{MHz}, 2450 \mathrm{MHz}$, and $5500 \mathrm{MHz}$, can be obtained. The contribution of this paper is to implement a simple and easy fabrication antenna for practical DVB and WLAN applications. The locations of the inserted slots on the dipole arms have been confirmed. The slots are located at quarter-wave length of the undesired frequencies from the feed point. Measurement results show that the structure indeed offers broad bandwidth and band rejection characteristics. Although this antenna was designed for DVB and dual ISM-band applications, its design concept can be extended to other frequency bands of interest.

\section{Acknowledgments}

This work was sponsored by the National Science Council, Taiwan, under the Contract no. 100-2221-E-228-001 and Wieson Corp. Tech. (http://www.wieson.com/), Taiwan, 

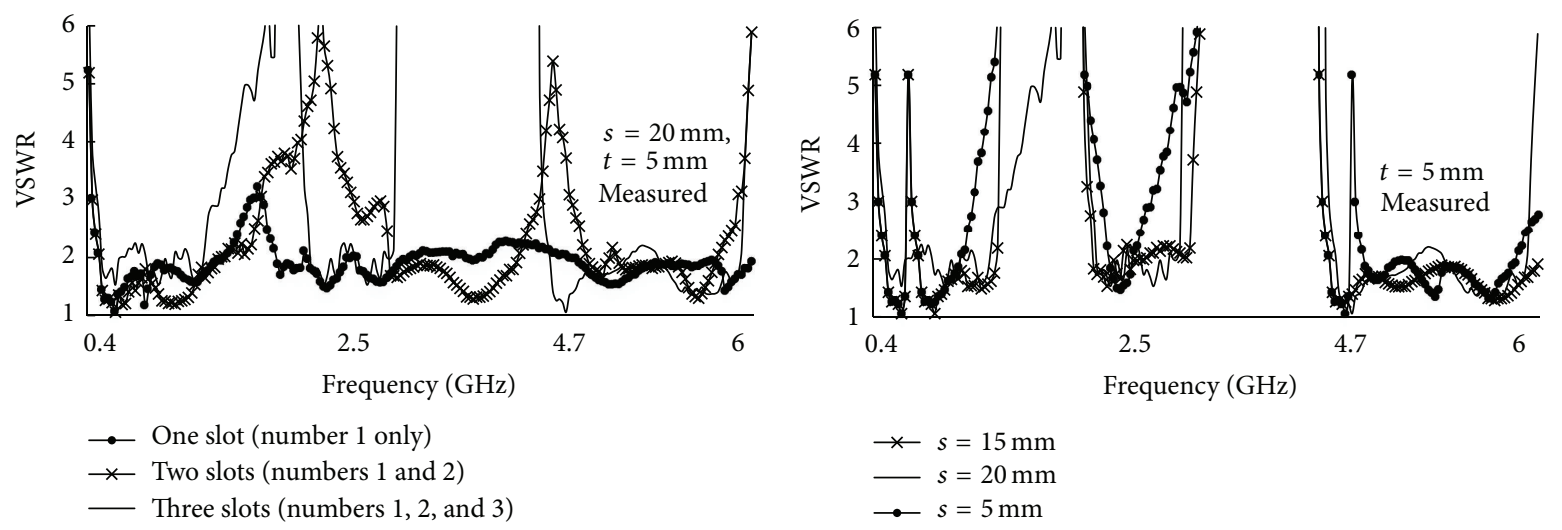

(a)

(b)

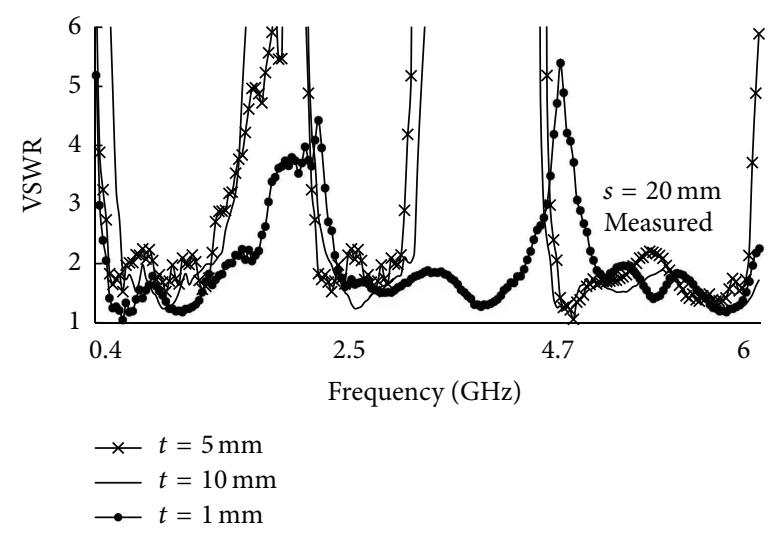

(c)

FIgURE 6: Measured VSWR as a function of (a) the inserting-slot numbers, (b) the inserting-slot length (s), and (c) the inserting-slot width $(t)$. Other dimensions are the same as given in Figure 1.

under Contract no. JW100-F-411-148. The authors also appreciate the reviewer's comments that improved the quality of this paper.

\section{References}

[1] D. Morris, P. Pangalos, and A. H. Aghvami, "Mobile terminal location discovery schemes for a "Beyond 3G" inter-worked network," in Proceedings of the sixth IEEE International Symposium on WoWMom, pp. 401-406, June2005.

[2] J. D. Kraus and R. J. Marhefka, Antennas, McGraw-Hill, New York, NY, USA, 2002.

[3] R. Jordan and C. T. Abdallah, "Wireless communications and networking: an overview," IEEE Antennas and Propagation, vol. 44, no. 1, pp. 185-193, 2002.

[4] C.-M. Peng, I.-F. Chen, C.-C. Hung, and H.-C. Chen, "Printed modified bow-tie dipole antenna for multi-band applications," IEICE Transactions on Communications, vol. 92, no. 4, pp. 14041405, 2009.

[5] Q.-X. Chu and Y.-Y. Yang, "3.5/5.5 GHz dual band-notch ultrawideband antenna," Electronics Letters, vol. 44, no. 3, pp. 172174, 2008.

[6] K. Chung, S. Hong, and J. Choi, "Ultrawide-band printed monopole antenna with band-notch filter," IET Microwaves, Antennas and Propagation, vol. 1, no. 2, pp. 518-522, 2007.
[7] D.-O. Kim, N.-I. Jo, H.-A. Jang, and C.-Y. Kim, "Design of the ultrawideband antenna with a quadruple-band rejection characteristics using a combination of the complementary split ring resonators," Progress in Electromagnetics Research, vol. 112, pp. 93-107, 2011.

[8] H. H. Yong, M. S. Deokong, and C. Kyoung:, "Wideband bow-tie monopole antenna having an improved band rejection characteristic," Korea Patent: KR 20080858969 B1, 2008.

[9] A. A. Gheethan and D. E. Anagnostou, "Dual band-reject UWB antenna with sharp rejection of narrow and closely-spaced bands," IEEE Transactions on Antennas and Propagation, vol. 60, no. 4, pp. 2071-2076, 2012. 

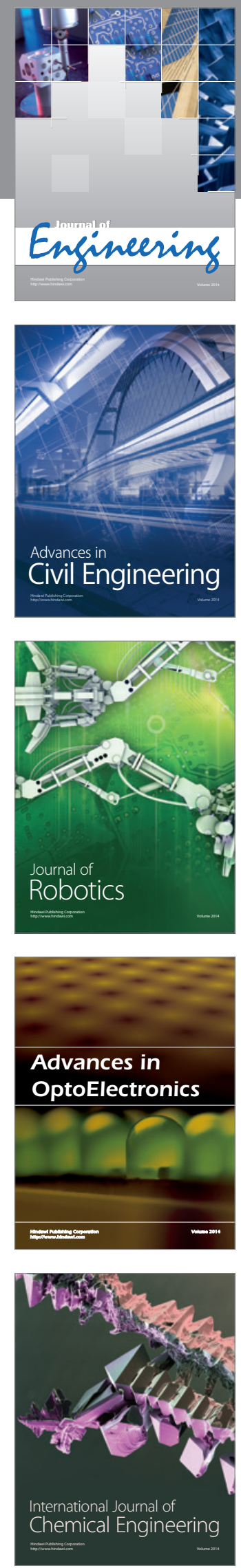

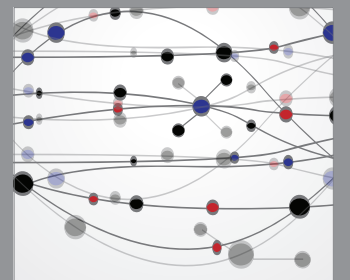

The Scientific World Journal
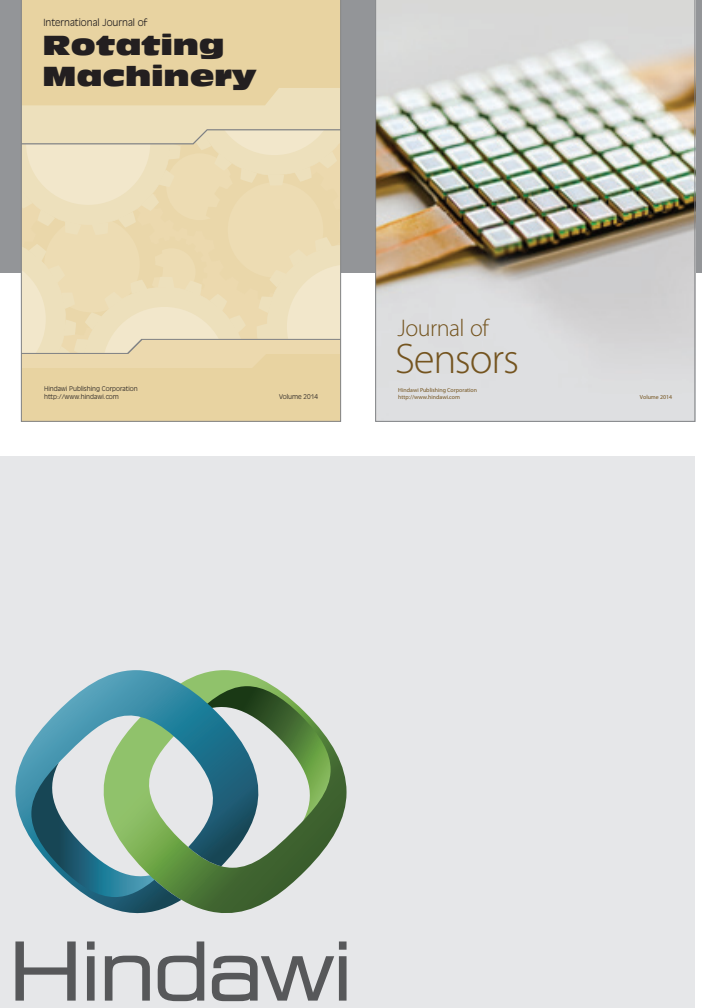

Submit your manuscripts at http://www.hindawi.com
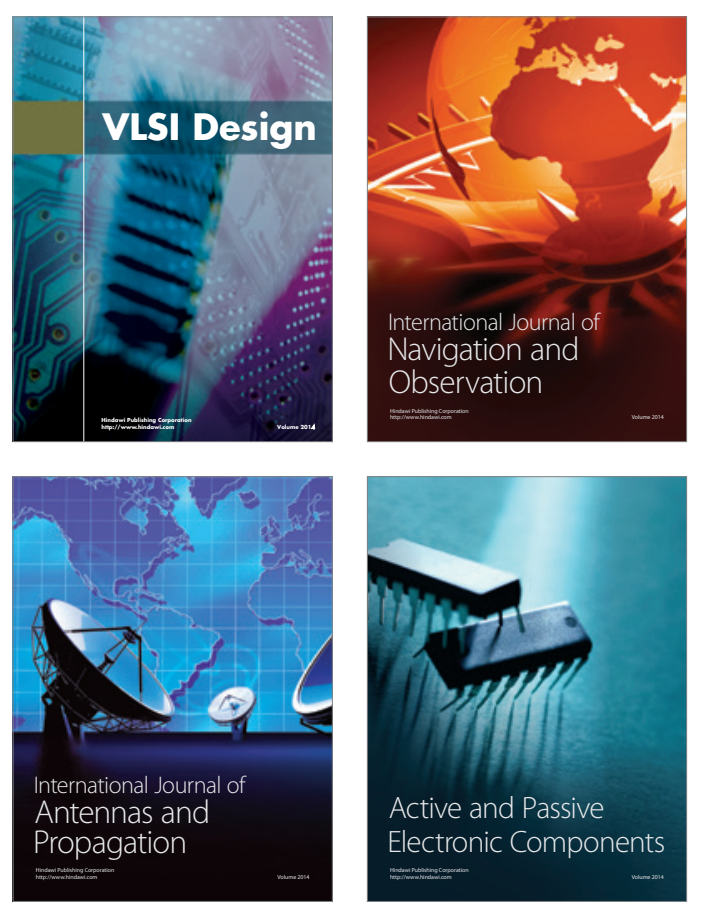
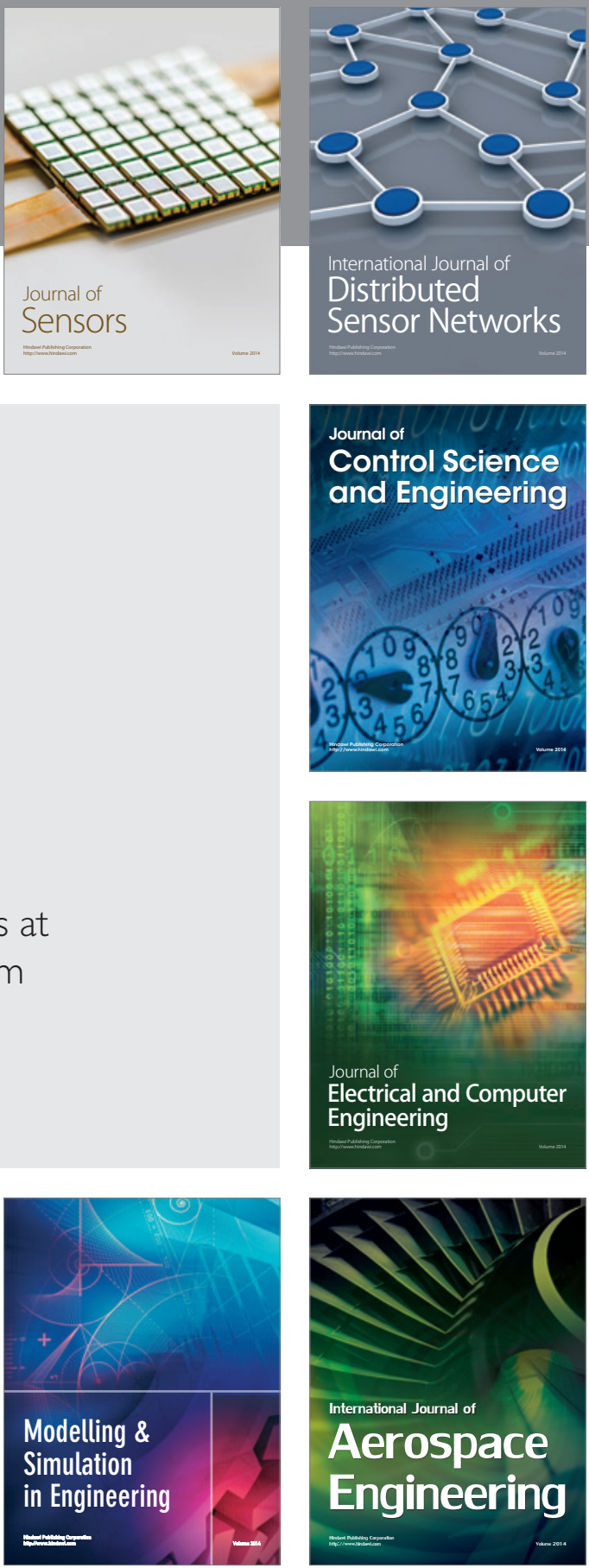

Journal of

Control Science

and Engineering
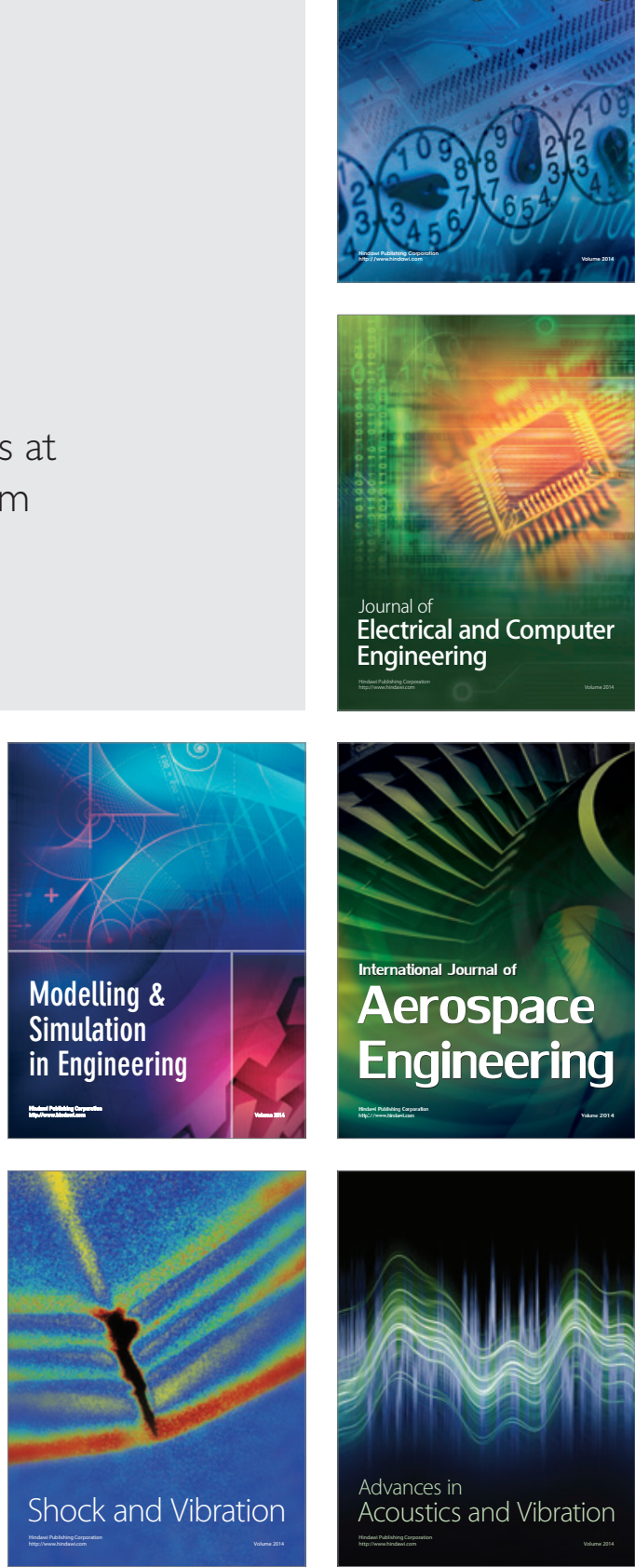